\title{
Remote Monitoring of Perforator Flaps Using an Innovative Device with an Application for Mobile Phone: A Pilot Study
}

\author{
Miguel de la Parra, MD ${ }^{1}$ Javier Montaño, MD ${ }^{1}$ \\ ${ }^{1}$ Division of Plastic and Reconstructive Surgery, Mexican Institute of \\ Social Security (IMSS), Monterrey, Nuevo León, Mexico \\ Address for correspondence Miguel de la Parra Marquez, MD, \\ Division of Plastic and Reconstructive Surgery, Mexican Institute of \\ Social Security (IMSS), Avenue Hidalgo 2480 pte, Col. Obispado. C.P. \\ J Reconstr Microsurg Open 2017;2:e37-e41. \\ 64060, Cons. 212, Monterrey, Nuevo León, México \\ (e-mail: drdelaparra@yahoo.com.mx).
}

\begin{abstract}
Background Surveillance and monitoring of perforator flaps has been well established for many years as a reliable method to detect early changes in the blood flow of the flap. In this manner, early flap revisions could be performed in cases of probable thrombosis.

Methods We performed a pilot study that included the first 12 patients to use this device. A temperature sensor electrode was used for remote monitoring of perforator flaps using a mobile phone in real time via a general pocket radio service and short messages developed by the authors, allowing the surgeon to check the temperature from any location.

Results The device continually displays the temperature of the flaps in real time performing a curve with measurements every 5 minute using the web page. A significant difference $(p<0.05)$ is shown between flaps with sufficient flow and flaps

Keywords

- perforator flaps

- remote monitoring

- mobile device

with venous thrombosis.

Conclusion Real-time direct thermography via the surgeon's mobile phone is a reliable method for flap monitoring, facilitating monitorization during the time when the surgeon is away from the hospital.
\end{abstract}

Surgical technique is considered the most important determining factor in the success of the flap, resulting in an overall complication rate with flap loss risk $<1 \%$. Another important aspect to maintain a high success rate is close monitoring of the flap to identify early variations of the inflow, allowing the possibility of early anastomosis revision surgery, resulting in a more favorable prognosis. ${ }^{1}$

Multiple methods for flap monitoring have been implemented over time; however, clinical judgment is still the most reliable method. ${ }^{2-8}$ Other methods used for monitoring perforator flaps are direct thermography, implantable Doppler, external Doppler, microdialysis, infrared oximetry flow, angiography, and images transmitted by electronic devices. These are but a few of the currently designed systems.,9-18

received

April 25, 2016

accepted after revision

May 26, 2016
DOI http://dx.doi.org/

10.1055/s-0036-1585087. ISSN 2377-0813.
The aim of this study is to report on a new device for temperature monitoring and its application for mobile telephones.

\section{Materials and Methods}

\section{Design of the Device}

The $15 \times 10 \times 5 \mathrm{~cm}$ device design is shown in - Fig. 1. The blue liquid-crystal display (LCD) screen and the external characteristics are displayed. Input power transmitter and radiofrequency antenna signal can be observed. The device has an output for the temperature sensor through a 2-m long cable.

This device works through a negative temperature coefficient medical grade sensor placed on the skin flap and
Copyright $\odot 2017$ by Thieme Medical Publishers, Inc., 333 Seventh Avenue, New York, NY 10001, USA. Tel: +1(212) 584-4662.
License terms

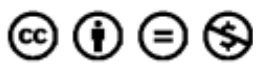



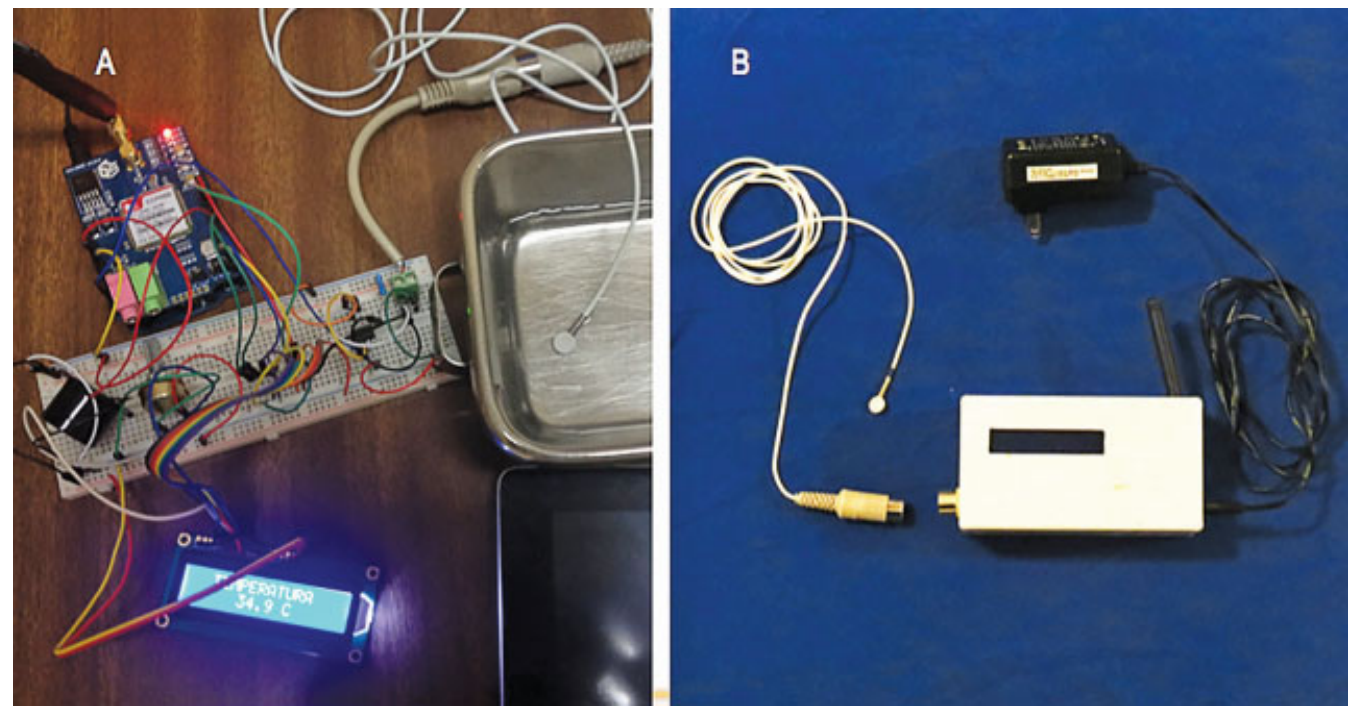

Fig. 1 (A) The ambulatory flap monitor before ensambling all the pieces. (B) The device fully finished as it looks actually.

attached with a common skin adhesive. The thermal signal is captured in the device designed by a microprocessor peripheral interface controller. The device is connected to a $16 \times 2$ character LCD display that shows temperature in real time (-Fig. 1).

The microprocessor uses, as a means of communication, a general pocket radio service (GPRS) modem to send data from a remote location (next to the patient's bedside) to the server and, in turn, to any mobile device (cell phone, tablet, etc.) (-Fig. 2). This communication between the device and server is achieved by sending data over the GPRS and short message service. The monitor is activated by software specifically designed for the device and features a range of programmable alarms according to user instructions. In our study, temperature was measured every 5 minutes and alarms were programmed at temperatures $<36^{\circ} \mathrm{C}$.

After the perforator flap surgery and once the patient is back in the hospital room, the device with the temperature's sensor is placed directly over the flap of each patient (-Fig. 3). Subsequently, we accessed the web application and measures with the established temperatures parameters were initiated (every 5 minutes, alarms at $<36^{\circ} \mathrm{C}$ ). Monitoring was continued during the first 48 hours after surgery and recorded in the corresponding software.

\section{Statistical Analysis}

SPSS v.10.0 (IBM Corp., Chicago, IL) for Windows was used for statistical analysis. Student $t$-test was used to compare the values of the temperature of the patient who developed venous thrombosis with the remainder of the patients. In addition, we analyzed all studied patients using a test of variance homogeneity (analysis of variance [ANOVA]); $p \leq 0.05$ was considered significant.

\section{Results}

Overall, 12 perforator flap procedures that met the selection criteria were performed from March 1 to May 31, 2015. The device was placed in all patients for temperature measurement. Data from patients were obtained from the recording sheet in the intended Web site.

Of the 12 patients, there were 4 males and 8 females; average age was 48 years ( \pm 14.4 years) (range: $18-75$ years). The most frequent flap analyzed was ALT $(n=6)$ followed by deep inferior epigastric perforators $(n=5)$ and fibula with skin paddle $(n=1)$. The breast was the most common anatomic region $(n=5)$ followed by the upper limbs $(n=2)$, Achilles tendon $(n=2)$, tibia $(n=1)$, and sternum $(n=1)$.

Of the 12 patients, only 1 (patient 5) showed venous congestion 6 hours after surgery, a 42-year-old female with multiple previous surgeries in the area of the Achilles tendon. Thrombosis was reflected in the monitor with an average temperature of $35.7^{\circ} \mathrm{C}$. Consequently, it was surgically explored and venous thrombosis was found in the main vessel. Thrombectomy of the pedicle artery and a new venous anastomosis were performed without complications. The remaining patients presented an above average temperature from 36.3 to $37.4^{\circ} \mathrm{C}$ (-Table 1).

Using Student $t$-test, temperature values from patient 5 were compared with the remaining patients, demonstrating a $p=0.001$ ( $95 \%$ confidence interval: $0.92-1.05$ ). Likewise, using a test of variance homogeneity (ANOVA), temperature results obtained for groups who showed good vascularity of the flap were compared ( $n=11, p=0.077$ ). Using the above statistics (ANOVA), temperatures were compared including patient $5(n=12)$, obtaining a $p=0.003$. 


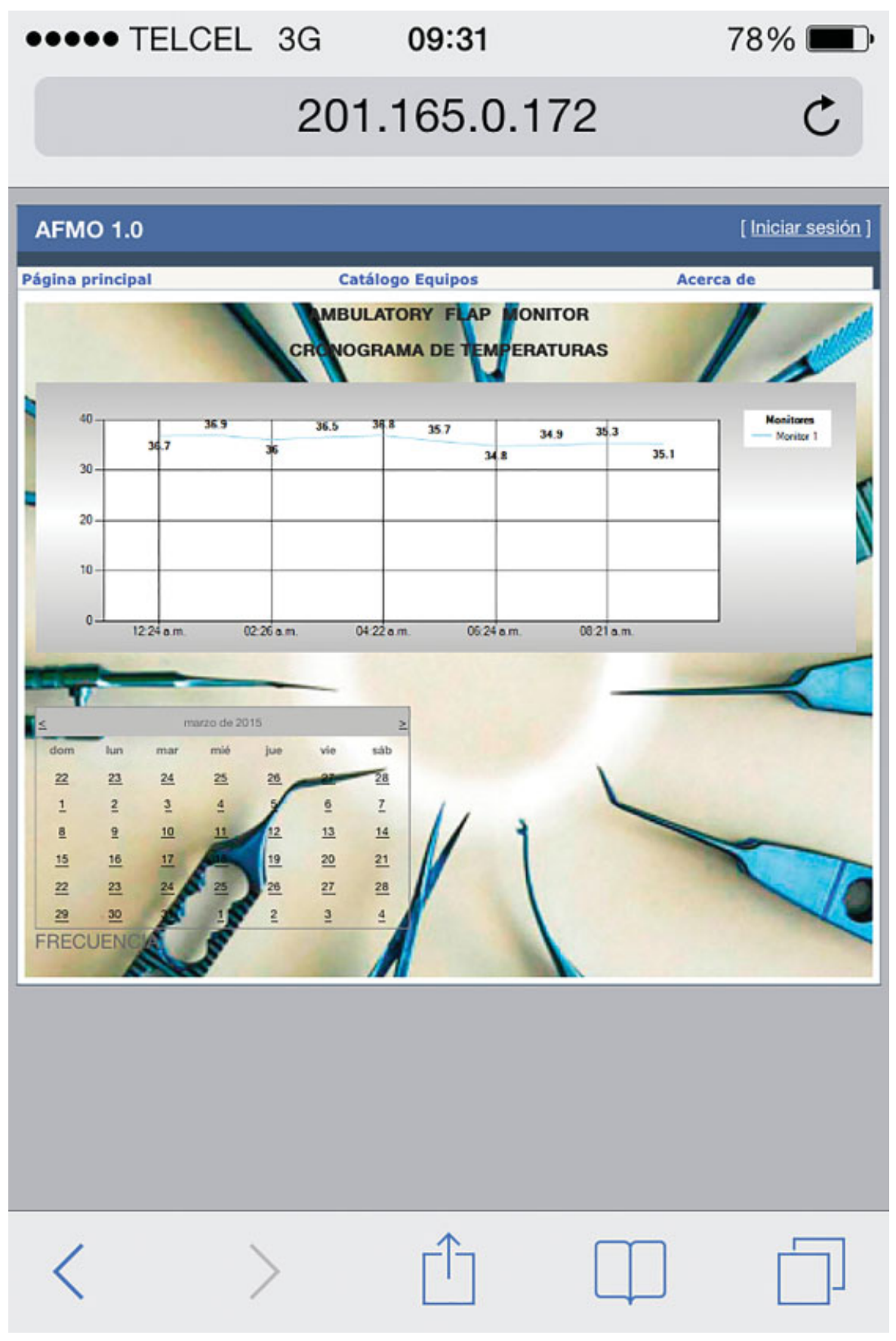

Fig. 2 Screen shot of a mobile phone with the web application running. We can see the temperature graph in real time.

\section{Discussion}

Perforator flaps are certainly the workhorse in most reconstructive cases that require soft tissue transfer. ${ }^{16-18}$ Surveillance and monitoring of fasciocutaneous flaps have been well established for many years. Personal surveillance has been the most common method because it does not require input material and is easily reproducible. However, it is totally dependent on the observer's experience. Currently, the most reliable method is the use of internal Doppler probes, which are placed beside the anastomosis and con- tinuously measure the flow. ${ }^{2-13,19}$ However, this method is not very popular in some countries such as Mexico because the cost of the device is unaffordable by most health institutions or by the patient.

Direct thermography has been well established as a reliable monitoring method and is used in many hospitals worldwide due to its low cost and easy interpretation. Our device is based on a receiver electrode with a porcelain covering that isolates room temperature and, in turn, sends the temperatures taken by the device in real time to the surgeon's mobile device. This is done every 5 minutes and 


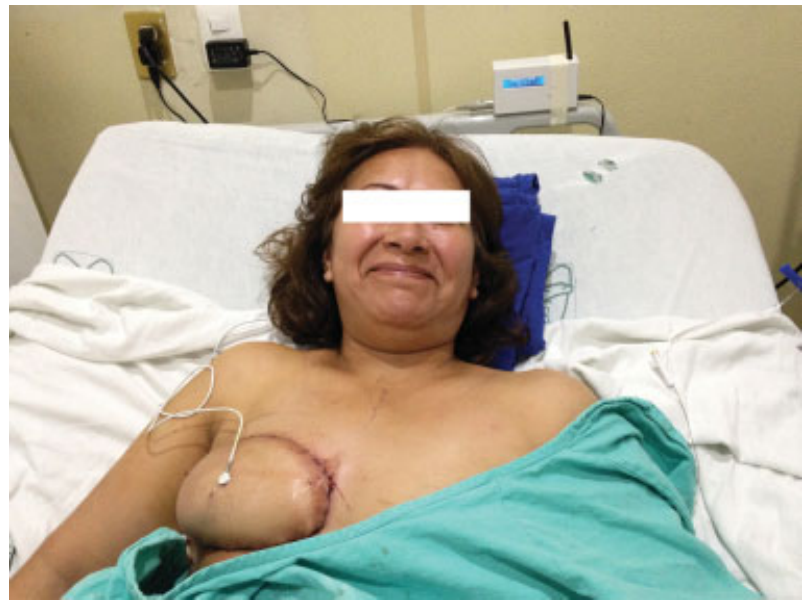

Fig. 3 The device applied to a patient with a deep inferior epigastric artery perforator flap for breast reconstruction.

sent to the cell phone. In this way, the surgeon checks the temperature from any location.

Another advantage of the device is the alert system via text message, which sends it automatically in case it records temperatures $<36^{\circ} \mathrm{C}$. Interpreting our results, it appears there are significant differences in the temperature of flaps that remained well perfused with those that presented venous thrombosis (patient $5, p=0.0001$ ). Similarly, no difference was observed in terms of temperature records of patients with good flow $(p=0.077)$ according to the test of homogeneity of variance of all patients. However, including the patient with venous thrombosis (patient 5 ), a difference is observed in homogeneity of variance with a $p=0.003$. These results show that the temperatures measured with the designed device are statistically different in

Table 1 Temperatures taken by the device in the patients who participate in the study

\begin{tabular}{|l|l|l|l|l|l|}
\hline $\begin{array}{l}\text { Patient } \\
\text { no. }\end{array}$ & Flap & Minimum & Maximum & Average & $\begin{array}{l}\text { Standard } \\
\text { deviation }\end{array}$ \\
\hline 1 & ALT & 34.8 & 37.3 & 36.73 & 0.37 \\
\hline 2 & ALT & 36.3 & 37.3 & 36.79 & 0.24 \\
\hline 3 & DIEP & 36.5 & 37 & 36.69 & 0.1 \\
\hline 4 & DIEP & 35.8 & 37 & 36.29 & 0.3 \\
\hline 5 & ALT & 35.2 & 36.8 & 35.7 & 0.19 \\
\hline 6 & DIEP & 36 & 36.9 & 36.54 & 0.26 \\
\hline 7 & Fibula & 36 & 37.2 & 36.6 & 0.21 \\
\hline 8 & ALT & 36.5 & 37.4 & 36.82 & 0.21 \\
\hline 9 & ALT & 36.2 & 37.3 & 36.73 & 0.21 \\
\hline 10 & ALT & 36.1 & 36.6 & 36.42 & 0.1 \\
\hline 11 & DIEP & 36 & 36.5 & 36.3 & 0.13 \\
\hline 12 & DIEP & 36 & 37 & 36.67 & 0.19 \\
\hline
\end{tabular}

Abbreviations: ALT, anterolateral thigh; DIEP, deep inferior epigastric perforators. patients with good vascular flow as opposed to the patient with venous congestion and secondary thrombosis.

\section{Conclusion}

Real-time direct thermography via the surgeon's mobile phone is a reliable method for flap monitorization, facilitating the procedure even when the surgeon is away from the hospital.

\section{Conflict of Interest}

None.

\section{Acknowledgments}

This device was manufactured by engineers Emigdio Olives Aldana and Rafael Montaño Bojorquez from Sinaloa, Mexico.

\section{References}

1 Van Waes C, Seidenstuecker K, Mahajan A, et al. The safety of the deep inferior epigastric artery perforator flap procedure: a prospective analysis in 1036 breast reconstruction patients. Plast Reconstr Surg 2011;128(4S):57. Doi: 10.1097/01.prs.0000406278.04351.a7

2 Furnas H, Rosen JM. Monitoring in microvascular surgery. Ann Plast Surg 1991;26(3):265-272

3 Halvorson E. The limited utility and high cost of implantable dopplers for head and neck free flap monitoring. Plast Reconstr Surg 2012;130(5S):13. Doi: 10.1097/01.prs.0000421712.97633.9f

4 Setälä L, Koskenvuori H, Gudaviciene D, Berg L, Mustonen P. Cost analysis of 109 microsurgical reconstructions and flap monitoring with microdialysis. J Reconstr Microsurg 2009;25(9):521-526

5 Neumeister MW. Free flap monitoring: keeping it simple and reliable. Plast Reconstr Surg 2006;117(3):1073-1074

6 Goodson AM, Payne KF, Simmons J, Jain A. Free-flap telemonitoring to the surgeon's handheld device: proof of concept. Microsurgery 2014;34(5):413-414

7 Keller A. Noninvasive tissue oximetry for flap monitoring: an initial study. J Reconstr Microsurg 2007;23(4):189-197

8 Smit JM, Zeebregts CJ, Acosta R, Werker PM. Advancements in free flap monitoring in the last decade: a critical review. Plast Reconstr Surg 2010;125(1):177-185

9 Abe Y, Hashimoto I, Goishi K, Kashiwagi K, Yamano M, Nakanishi $\mathrm{H}$. Transcutaneous PCO2 measurement at low temperature for reliable and continuous free flap monitoring: experimental and clinical study. Plast Reconstr Surg Glob Open 2013;1(2):1-8

10 Swan MC, Wilson HA, McGuiness CN. Free flap temperature homeostasis during microsurgery: benefits of the "microsurgical duvet". J Reconstr Microsurg 2013;29(8):561-564

11 Kruse AL, Luebbers HT, Grätz KW, Obwegeser JA. Free flap monitoring protocol. J Craniofac Surg 2010;21(4):1262-1263

12 Hashimoto I, Nakanishi H, Takiwaki H, Takase MT, Yamano M, Sedo H. Flap monitoring by transcutaneous $\mathrm{PO} 2$ and PCO2: importance of transcutaneous PCO2 in determining follow-up treatment for compromised free flaps. J Reconstr Microsurg 2007; 23(5):269-274

13 Lohman RF, Langevin CJ, Bozkurt M, Kundu N, Djohan R. A prospective analysis of free flap monitoring techniques: physical examination, external Doppler, implantable Doppler, and tissue oximetry. J Reconstr Microsurg 2013;29(1):51-56 
14 Chen Y, Shen Z, Shao Z, Yu P, Wu J. Free flap monitoring using nearinfrared spectroscopy: a systemic review. Ann Plast Surg 2016; 76(5):590-597

15 Sue GR, Kim R, Chen W, Narayan D. Real-time free flap monitoring using a standard video camera: a lower cost and simpler option? Plast Reconstr Surg 2014;133(6):905e-906e

16 Kempton SJ, Chen J, Poore S, Afifi A. Abstract 96: the venous anastomotic flow-coupler for free flap monitoring: a prospective analysis of 85 microsurgical breast reconstruction cases. Plast Reconstr Surg 2014;133(3, Suppl)111. Doi: 10.1097/01.prs.0000444920.45830.5d
17 Chen KT, Mardini S, Chuang DC, et al. Timing of presentation of the first signs of vascular compromise dictates the salvage outcome of free flap transfers. Plast Reconstr Surg 2007;120(1):187-195

18 Wei FC, Jain V, Celik N, Chen HC, Chuang DC, Lin CH. Have we found an ideal soft-tissue flap? An experience with 672 anterolateral thigh flaps. Plast Reconstr Surg 2002;109(7):2219-2226, discussion 2227-2230

19 Sakakibara S, Hashikawa K, Omori M, Terashi H, Tahara S. A simplest method of flap monitoring. J Reconstr Microsurg 2010;26(7):433-434 